\title{
SMS Language and College Writing: The Languages of the College Texters
}

\author{
doi:10.3991/ijet.v5i1.1010 \\ Latisha Asmaak Shafie, Norizul Azida, Nazira Osman \\ Universiti Teknologi MARA Perlis, Malaysia
}

\begin{abstract}
Many students have become avid texters and are seriously reinventing language to accommodate the 160character limit of short messages. They are more interested in getting their messages across and thus becoming less concerned about correct spelling, grammar and punctuation. Since texting has become a way of life of many students, it is feared that the SMS language can affect students' written performance. This research examines the effects of frequent usage of text messaging (SMS) on undergraduates academic writing. For the purpose of the study, 264 Diploma students of UiTM Perlis were selected as participants. They were 94 male texters and 170 female texters aged between $18-22$ years old who were taking three different English courses namely Preparatory English, Mainstream English 1 and Mainstream English 2. The data includes participants' SMS messages, class assignments and examinations scripts which were analyzed in order to detect the existence of SMS language by using measuring instruments of Orthographic forms (Shortis, 2001). The findings reveal that there were few occurrences of SMS language in students' examinations scripts among weak students
\end{abstract}

Index Terms-texters; academic writing; orthographic forms, SMS language;

\section{INTRODUCTION}

The role of written language has clearly changed during the last decades where the computer and the emergence of new information and communication channels play an important role. A great deal of our communication occurs by means of writing, which in addition to traditional pen and paper, is mediated by the computer, the Internet and devices such as mobile phones. Word processing and sending messages via email are among the most common activities on computers today. Texts are produced easily and rapidly with current technology. In fact, with this advancement, more adults, students, teenagers and children prefer to communicate with each other using text messages.. Computers and new media are introduced and used more and more in schools.

Written language is in general standardized with less (dialectal) variation compared with spoken language. Learning a written language means not only acquiring its more or less explicit norms and rules, but also learning to handle the overall writing system (Teleman, 1991). One learns how to segment words, form clauses and express themselves in many different contexts and for different purposes. One learns to master grammatical, discursive and strategic competence to convey a thought or message to the reader.
Nowadays, the popular channels of communication that enables written interaction are web chat and instant messaging on the internet, as well as text messaging (SMS) via mobile phones. Some say SMS is an aberrant world of abbreviations, numerals and pictorial icons. The truth is, SMS has rewritten the way we communicate. But, more importantly, SMS has made humans let their fingers do the 'talking'. Interestingly, it makes people more chatty, articulate and open. Texts used in SMS are produced mostly at all times with the aim of saving time, effort, and even cost because it is much cheaper to send messages via SMS than making calls. Since SMS has become the 'useful' tool of communication nowadays, formal language is under serious threat. What we are witnessing are 'antiformal communication structures' that have alarmed linguists and language purists alike.

Thus, several questions have been raised especially among teachers because they feel that by using SMS languages, it can affect the students' especially among teachers because they feel that by using SMS languages, it can affect the students' performance especially in their writing ability and product. How do students and adolescents use writing today? How does information technology influence the acquisition of writing? Is the use of writing in new media a threat to the standard written language? How can information technology be better used to support the writing process? These questions to them need to be looked into.

Text Messaging System or Short Message System (SMS) allows users to send and receive short messages from handheld, digital mobile phones or from a computer to a mobile phone, giving almost instant access to others to connect. Young people in particular, have taken to the SMS technology and are adapting and inventing language to accommodate the 160-character limit of short messages which has implications for communications and language use. Text messaging is known as a popular tool among teenagers to send jokes, riddles, invitation to parties and other information to their friends. Texting has become a way of life of many teenagers, in particular, students, since most of them own and use mobile phones in their daily life. This phenomenon has one way or another give birth to a new dialect. The grammatically correct sentences and correct spelling of English words have been affected.

This is because avid texters usually delete vowels, substitute letters for number or symbols and deliberately misspell words using the phonetic spelling. They are more interested in getting their messages across and becoming less concerned about correct spelling, grammar and punctuation. Problems arise when students use this SMS language in their academic writing particularly in their writ- 
ten examination paper. Therefore, this study was carried out to indicate whether the students of Universiti Teknologi Mara (UiTM) Perlis use the various text message shorthands and whether the SMS language affects their writing performances. Thus, the study was undertaken with the objectives to determine whether texters fulfil the sociolonguistic maxims of SMS and to ascertain the typology of text language used by these texters.

\section{LITERATURE REVIEW}

In this part, the researchers review literature related to the issue at hand and in particular English Language Teaching at the university level; learners' perspective of learning writing as well as the lecturers' perspective in terms of teaching writing. The review also includes studies on language used in emailing, in IM and in text messaging.

\section{A. The Importance of Writing}

Writing is one of the productive skills in language learning besides reading and the other two receptive skills that are listening and speaking. All the four skills are required in order to become competent in English Language. However, in certain situations, the emphasis might differ and depend entirely on an individual's needs and preference. In Malaysian context, undergraduates in the local universities are still having difficulties in expressing themselves well in writing in the target language. This might be because the students do not have a strong foundation in the rudiments of basic grammar and therefore are unable to put down their ideas or points effectively in written form. In most situations, the lack of grammatical competence and written practice causes most students to be anxious, self-conscious and uncomfortable, automatically making writing a dreaded task.

Writing is undoubtedly the central issue in second language learning. Writing requires the mastery of language as the students need to explore the language and become involved in the language (Raimes,1983).It has been established that the fundamental function of writing is for communication in prose form. Writing is more demanding and needs formal instruction unlike speaking, which can be acquired naturally. Furthermore, a clear distinction needs to be made regarding the fact that being able to speak English adequately does not necessarily mean being able to write well. Thus, good acquisition of one skill does not automatically guarantee good performance in other skills. As highlighted by Raimes (1983:4), "learning to write is not just a natural extension of learning to speak a language.” Raimes also postulates that although learners can acquire their first language at home with minimal systematic instruction, they still need formal instruction on how to write in the same language. It is also common to find that many adult native speakers of a language find writing difficult.

E.B. White, an American essayist, who is known for his great work, confessed, "Writing....is a hell of a chore for me, closely related to acid indigestion" (Nadell, et.al. 1994). If the task of writing was so traumatic for a prolific writer like White, what more the students; the apprehension and fear they experience when required to produce a piece of written work. Basically, most of the anxiety and distress stems from students' lack of form (grammar and sentence structure), which subsequently hinders their con- tent (meaning and ideas). Thus, the combination of students' grammatical incompetence and the pressure to excel during written examinations, adds to their apprehension, which results in their inability or reluctance to write. Nonetheless, though writing is a difficult skill to acquire and master, it has significant qualities, which aid in daily communication.

Therefore, writing requires students to use the other three skills in tandem and thus becomes the testing ground for all the linguistic skills learnt by the learners.

\section{B. The Writing Skill in UiTM}

As for UiTM undergraduates, it is compulsory for them to take English courses in their first and second year of studying and if they fail this subject, they are unable to graduate. Students not only have to read and prepare for these written tasks in English but most importantly, they have to write accurately, creatively and convincingly to score marks. Therefore, the pressure to have good writing skills is tremendously high on these undergraduates. Unfortunately, it is in the area of writing skill that most of them fail miserably. Thus, it is considered pertinent to study the weaknesses and errors in the students' writing and also to see whether their daily text messaging system has somehow or rather influenced their writing performance.

Herring (2001) suggests that language will necessary be affected by technological (or medium) variables such as asynchronous, granularity (how long or short the text could be) and multimodality as well as other nonlinguistic variables such as participants' relationships, expectations and levels of motivation. SMS and email may define as asynchronous, text-based and technologically mediated discourse. Biesenbach-Lucas \& Wiesenforth (2001) state that electronic communication imposes new demands on language that causes interesting variations in written language use.

The use of e-mail in second language learning can be used in the studies of text messaging as they are similar in term of allowing instantaneous communication and can be stored for later retrieval and review. Ehrmann (2000) points out from the users' perspective, an important similarity is that both texts and emails can be composed with or without a self-conscious planning or structure which allow students to communicate at their own speed. Tella (1992) investigates cohesive structures, lexicon and rhetorical features in the email writing of Finnish secondary students writing in English. The results suggest that e-mail texts resemble oral communication where ellipsis and colloquialisms were more prominent in e-mail texts than in word-processed essays.

Biesenbach-Lucas \& Weasenforth (2001) indicate that in their analysis of ESL students e-mail and wordprocessed writing that students' use of grammatical and lexical cohesive devices may be influenced by a complex combination of medium, task situation and audience and native language as well as language proficiency and familiarity with e-mail. Happel (19) predicts the trend of using email notifications in software applications being converted to SMS targeting teenagers as the main expected user group. Baron (1998) in her quest to prove that email might herald a new linguistic genre concludes that email language rather represented a creolizing blend of written and spoken discourse. Baron (2001) states that 
email is speech-like because writing in general has become more speech-like as contemporary patterns of education and technology influence the present writing trends. Are all these pointing to an entirely new trend in English Language? Will this lead to a distortion of the language or is it just another fad? Besides, there is no danger of unlearning what they have learnt, as they are conscious of using the language at different levels-with their peers, with elders and in official correspondence.

As for instant messaging, it is similar in some aspects to SMS. In comparing IM with SMS, Baron and Ling (2003) found that communications are often composed quickly and in an informal style. The language of IM and SMS are similar in that they reduce attention to spelling, punctuation, and grammar with words like " $4 u$ " ("for you") or "2gthr yrs 18r" ("together years later”). Whether it was also true for UiTM Perlis students were not known since similar linguistic related studies were not currently available.

Crystal (2001) predicts that instant messaging affects languages due to the usage of emoticons, abbreviations and communicative features as languages are adapted to meet new needs and interactions. Segerstad (2005) believes that SMS language mimics the spoken word. He concluded that the usage of misspelled words, abbreviations were to serve interlocutor time, space and efforts.

Tagliamonte and Denis (2008) in their research on natural instant messaging of 72 teenagers between fifteen to twenty years old conclude that instant messaging is a hybrid form of communication which comprises of colloquial language and formal language. It is more formal than the spoken language but less formal than written language. Short forms are usually used by younger users of IM. This finding was supported by Ling and Baron(2007) in their investigation of linguistic characteristics of instant messaging and text messaging find that Instant messaging exhibit creative phenomena similar to text messaging, although at a lower frequency (Ling and Baron, 2007).

\section{The Rise of Text Messaging System}

The question that arises now is, is messaging changing the way we especially students write and speak? Is this the beginning of a new language or is this the death knell for written English? Text messaging has revolutionized spellings and threw grammar out the window. With the increasing use of mobile messaging, emails, and instant chat, people are becoming less concerned about correct spelling and more interested in getting their message across. There is no time for commas and full stops, no time to frame sentences or even words. Words are spelt phonetically and sentences are telegraphic. For the unaccustomed eyes such messages may be Greek and Latin, but for the young generation, that is the way communication is going to be.

Even though SMS is the latest and most popular media innovation we have witnessed, there seems to be very little academic research into this form of Text Language. Most of what little literature available have focused on the sociolinguistic aspects of Text Language particularly its use and its effects on the user's native language (Mander,G., 2001; Hulme,M. and Peters, S., 2002; Taylor, A.S. and Harper, R., 2002; Hard af Segerstad, Y., 2002; Thurlow, C., 2003; Davide, A., Dario, B. and Tal, D., 2004). The main concern among educators is the possibility that using text language will have negative effects on the traditional grammar of the user's language. However, this may not be the case. Kasesniemi and Rautiainen (2002), in studying SMS use by teenage Fins, reported that Finnish teachers were worried about the negative effects of SMS use by schooling teenagers because "SMS communication does not rely on traditional grammar or punctuation required for texts written for school." However, they observed positive benefits especially for boys who "have a tendency to resent official teaching of Finnish" and because "the unique writing style provides opportunities for creativity." Similar socio-linguistics studies with respect to UiTM Perlis students were not available.

In mobile learning, the ability of humans to adapt technology for uses that would not previously be considered humanizes the concept. Halliday(1990) notes that when users write using the mediums they never had to do, the language used would be altered and become a different language in order to cope with such impose (p.82). Halliday (1990) predicts that the demands and functions imposed on computer-mediated communication (CMD) would produce varieties of formal properties of the language used. Murray (1988) says that it is the result of the specific context of the situation (p.370) which determines oral or written features in any discourse. Common sense would determine that people use technology that is appropriate for the task.

Lambrinidi \& Depasta (2004) conclude that SMS language is not a stable language as it is multifunctional and context depended. In addition to that, the technical characteristics and conditions of mobile text messaging play an important role in the heuristic of this new form of communication such as a synchronous communication, limited message size, constrained message length, a tiny key pad with its few and small keys, small screen and limited message size which require careful editing and elicit the most interesting consequences.

Thurlow(2003) in his research on discursive analyses of qualitative data of 159 older teenagers' use of mobile telephone text messaging examined the linguistic forms and communicative functions in a corpus of 544 participants' actual text-message. Thurlow (2003) investigates on reasons of young people use text-messages and the extent they experiment with conventional language in their text messages. Regarding the language of the SMS, Thurlow (2003) notes that mobile phone text messages (SMS) have similar hybrid quality with email and most CMD not only in term of speech-writing blend but also in terms of old and new linguistic varieties. Thurlow(2003) concludes that the linguistic and communicative practices of textmessages emerge from a particular combination of technological affordances, contextual variables and interpersonal priorities. In term of the sociolinguistic maxims of SMS, SMS appears to undertake three key sociolinguistic maxims stated by Grice (1975) such as brevity and speed as manifested in abbreviation of lexical items (letter-number homophones) and minimal use of capitalization and standard, grammar punctuation (eg commas and space between words).

Thurlow (2003) explains that the need of brevity and speed appears to be motivated less by technological constraints but by discursive demands such as ease of turntaking and fluidity of social interaction. The other two maxims are paralinguistic restitution (loss of socio- 
emotional or prosodic features as stress and intonation) and phonological approximation.

Thurlow (2003) claims that the SMS language is exclusive and incomprehensible to outsiders are clearly exaggerated. SMS users know how to exercise the need for certain intelligibility in term of quantity and manner (Grice, 1975). For example, the use of consonants than the vowels (Eg THX for thanks) as consonants in English carry semantic meaning than vowels. In addition to that, many non-conventional spellings for example skool or the use of $\mathrm{z}$ for girls is universally comprehended.Furthermore the typhographic practices of textmessaging offer more useful representations of speech than the actual spellings. Thurlow (2003) explains that the teenagers write their text messages informally which result in producing 'small-talk ' and create the desired social bond. The language they use is not only comprehensible but also appropriate to the overall communicative function. Thurlow (2003) concludes that new linguistic practices are often adaptive rather than necessarily substractive as young text-messagers manipulate conventional discursive practices with linguistic creativity and communicative competence in their pursuit of intimacy and social intercourse.Weatherall (2004) studies the text message of 16 secondary schools students in Wellington and detected changes in language and the way young people communicate through their mobile phones. She finds that language has been manipulated not only to suit the medium of the text message which was to make them easier to send but also to signify a youth social identity. Weatherall concludes that text messaging has a major impact on language as some dictionaries have already included text words.

In conclusion, text messaging is found to be part of teenagers' life nowadays and have a major impact on them. As such, we have yet to see whether text messaging has a great influence on the students especially in the academic writing.

\section{Methodolgy AND PROCEDURE}

\section{A. Population}

This study involved 264 texters (participants) of UiTM Perlis.Their national medium was Bahasa Malaysia.There were 94 male texters and 170 female texters.The study involved of 6 classes; two classes of first semester students, two classes of second semester students and two classes of third semester students. The research was conducted in one semester. The texters represented the age range of most UiTM Perlis students as their age range was between 18-22 years old. The texters possessed hand phones and they had the habit of sending SMS messages not only to their friends but also to their respective lecturers.Thus this habit allowed the researchers to compile the corpus of SMS language which the texters used in their daily lives. The corpus enabled the researchers to construct typography of SMS language which determined whether the SMS language influenced and affected their academic writing.

\section{B. Sampling}

The sample was purposive sampling. The study involved of 6 classes ;two classes of first semester students, two classes of second semester students and two classes of third semester students. The research was conducted in a duration of one semester. The texters were selected be- cause they were registered in these English subjects and under the supervision of the researchers throughout the semester. The reason for doing so was so that their SMS messages could be collected and recorded for the duration of the semester by the researchers. Thus, any appearance of SMS language in their class assignments and examination scripts were detected and noted by the researchers. As a purposive sample, each texter was asked to retrieve from their phones English SMS messages that they had either sent or received throughout the semester and to transcribe them as accurately as possible (i.e.'exactly as they appeared on the display screen'). This was done throughout the semester.The texters were assured of the confidentiality and anonymity of their responses; this was important given the personal nature of the message.

Instructions were given to submit only English SMS messages that the texters had sent or received from their mobile phones. They were also asked to refrain from sending in any repetitive messages.After filtering the obvious noisy inputs, a total of 2640 genuine SMS messages were collected from 264 texters.This wide sample based enhance the breadth of the corpus, which helps to ensure that results derived from the model reflect a diverse population of users.

\section{Research Design}

The study adopted a design that would enable the researchers to determine texted English(SMS language) resembles oral or written discourse and whether texted English is used during class assignments and examinations.Data were collected through documents such as SMS messages, class assignments and examination scripts. From the text messages collected from the texters, a typology of Texted English used by the texters was constructed using Shortis (2001). The typology of Texted English enabled the researchers to detect the existence of Texted English in their academic writing. In lieu with this, the researchers collected and evaluated texters' writing assignments and examination papers to check whether their academic writing was influenced by the usage of texted English and to determine the nature of discourse of texted English by using Nunan(1993).

\section{The Typology of Texted English}

The orthographic forms are the combination of English and their first language (Bahasa Malaysia). Contraction is a common form as shortening the word or expression saves time in writing and typing. Contractions were widely being used by deleting and adding the syllables and deleting weak vowels. Numbers, foreign words and symbols were used to indicate playfulness in text messages and to economize time in typing texts. In Texted English, texters had their own preferred spellings of words when they type their own text messages. Thus, in Texted English, there are many variants of the same word.

\section{E. Written vs Oral Discourse}

The unique conditions of the mobile text messaging such as asynchronous communication, limited message size and message length and a tiny key pad with its few small keys and small screen which requires careful editing and creativity dictates the heuristics of SMS language ( Lambrinidi \& Depasta,2004). The language is influenced by the manner of production, and contextual features. SMS language resembles the hybrid combination of writ- 
ten and spoken discourse. SMS language is in form of written discourse as it takes slower activity, permanent and be consulted and portable.Whereas,SMS language is in form of spoken discourse as the speed and manner of production is important and it requires on-line editing and negotiated meanings. Compared to standard written language, SMS language is often reduced in a number of ways such as reductions of subject pronouns, words and speech-imitating spelling. These reductions often reflect a speech-like quality.

SMS language is in form of written as written texts are decontextualised or autonomous as there is no-face-toface interaction. The situation has to be inferred from the text. Meaning is conveyed through words. Visual clues such as body gestures and auditory clues like variation in tone of voice, hesitations, pauses etc are replaced with emiticons. In contrast to that finding, SMS language is similar to spoken discourse as it requires on-line monitoring which is resulted from addressee's immediate feedback.. According to Lambrinidi \& Depasta (2004 ), the form of text messages is written yet SMS language includes many elements of oral speech in form of the usage of dialectal words and expressions. The SMS language depends on the receiver, sender, the relation between them, their education and the purpose of the message.As SMS language is multi-functional and context depended language, SMS language is not stable.

\section{F. Texted English in Academic Writing}

Texters preferred to write 'u' rather than 'you '. Texters knew how to use proper English when writing essays. Texters knew when to use which language during formal and informal situations so participants did not use Texted English. There was awareness among the texters that Texted English was not used during academic writing in form of their class assignments and examinations. This suggested that texters knew different styles of language to be used during formal and informal situations. This ability to switch and use the language accordingly enable texters to use proper English and Texted English appropriately. Yet there were surprisingly a lot of spelling errors in class assignments. This finding suggests that by using a lot of Texted English which has different orthographic forms, texters might not able to recall the right spellings when the situation arises. Another interesting finding is Texted language only influences the language of texters who have weak proficiency in English.

During class assignments, the abbreviations ' $\mathrm{u}$ ' to replace 'you', 'wat' to replace 'what ' are popular. Eg: : Finally, check wat u have bought before leaving the shop. $\mathrm{U}$ should also be careful.

Apart from that, participants were able to discern between formal language and texted English. Yet there were many grammatical and spelling errors appeared in their assignments.

- M1: Although, that thing is similler,

- M2: We should buy neseccary things

\section{G. Examinations}

Few texters used the orthographic form in their examination scripts. Most of them used proper English when writing their essays. There was an awareness of not using Texted English when writing for academic purposes such as during examinations. They knew that during examina- tion, they had to use the proper spelling. Texters knew how to switch and use the language accordingly. Yet there were surprisingly a lot of spelling errors both in class assignments and examination scripts. By using a lot of Texted English which has different orthographic forms, the participants were not able to recall the right spellings when the situation arises. Another interesting finding is texted language only influences the language of those who have weak proficiency in English.

Few SMS abbreviations such as 'wut ‘, 'u' and 'ar' appeared on the examination scripts. It might be due to the reason that participants were consciously aware that during examinations which they were required to write for academic purposes, they were required to use the formal English language. In contrast, there appeared to be many spelling and grammatical errors.

Laurilla ( 2003 ) in her study revealed that college students were able to distinguish formal language from nonconventional texted English.There was no significant differences in grammar and spelling which revealed that frequency of texting had no effect on their grammar and spelling. Frequency of texting only had effects on grammar and spelling competencies on students whose language and communication skills at beginner level. This study revealed that there were many grammatical and spelling errors made by the participants during their examinations.Such finding supported the claim that most of the participants' proficiency levels are at the beginning level. The finding also raised the possibility that the daily usage of SMS language further eroded their proficiency in formal English. Their further participation in SMS language would cause participants to not know how to write decent formal English.

\section{CONCLUSION}

The research reveals several interesting findings. There is an awareness among the participants that texted English mustn't be used during academic writing in form of their class assignments and examinations. This suggests that students know the different style of language to be used during formal and informal situations. This ability to switch and use the language accordingly enable young people to use proper English and texted English appropriately.Yet there are surprisingly a lot of spelling errors both in class assignments and examination scripts. This finding suggests that by using a lot of SMS language which has different orthographic forms, the participants are not able to recall the right spellings when the situation arises.Another interesting finding is texted language only influence the language of those who have weak proficiency in English.

\section{REFERENCES}

[1] Ahn. "Discourse analysis in the language on the network," The Sociolinguistic Journal of Korea, 8(2),2000,pp 139-168.

[2] Bodomo A., Lee C.K.M.“Changing Forms of Language and Litteracy: Technobabble and Mobile Phone Communication,” Litteracy and Numeracy Studies,12(1). Singapore.

[3] Crystal,D.Language and the Internet. Cambridge:Cambridge University Press.2001.

[4] Georgakopoulou, A and D Goustos. Discourse analysis: An introduction. Edinburgh: Edinburgh University Press. 1997.

[5] P. Grice. “ Logic and conversation,”In P. Cole and J.L. Morgan, (eds.): Syntax and Semantics, Vol. 3, Speech Acts, New York, 
Academic Press, 1975, 41-58. Reprinted in P. Grice: Studies in the Way of Words, Harvard University Press, Cambridge MA, 1989.

[6] Grinter, R. E., \& Eldridge, M. A. “y do tngrs luv 2 txt msg?,” In W. Prinz, M. Jarke, Y. Rogers, K. Schmidt, \& V. Wulf (Eds.), Proceedings of the Seventh European Conference on Computer Supported Cooperative Work, 16-20 September 2001, Bonn, Germany Dordrecht, Netherlands: Kluwer Academic Publishers.2001,pp. 219-238).

[7] Hård af Segerstad, Y. Use and Adaptation of Written Language to the Conditions of Computer-mediated Communication. Department of Linguistics, Göteborg University, Göteborg.2002.

[8] Harlina,Y, Norizan,A.R. "An Analysis of e-mail among distance learners:Its implications to language learning and teaching,"In Proceedings of SALT 2004 Pulau Pinang.2004.

[9] Kasesniemi, E.-L.Mobile Messages. Young People and a New Communication Culture. Tampere: Tampere University Press,2003.

[10] Kasesniemi, E.-L., \& Rautianinen, P. “ Mobile culture of children and teenagers in Finland,” In J. E. Katz \& M. Aakhus (Eds.), Perpetual Contact: Mobile Communication, Private Talk, Public Performance Cambridge: Cambridge University Press,2002,pp. 170192. (doi:10.1017/CBO9780511489471.014)

[11] Kim, J. “Dangers of Internet language destruction,”.Korea Times, p.c 11,Jan 102005.

[12] Lambrinidi, A. \& Depasta, I. Greek Language And Mobile Text Messaging(SMS).2004. Retrieved 20 April 2006 from http://www.lsa.umich.edu/UofM/Content/modgreek/document/

[13] Meskill,C., Mossop,J., \& Bates,R."Bilingualism, cognitive flexibility and electronic literacy,” Bilingual Research Journal, 23(2/3),1999,pp113-124.

[14] Noh, H. (2000). "A study on chatting expression in Korean,” The Sociolinguistic Journal of Korea, 8 (2),2000,pp107-137.

[15] Nunan, D. Introducing discourse analysis. England: Penguin English,1993.
[16] Pennycook, A. "Incommensurable discourses?,”Applied Linguistics,15, 2,1994,pp 115-38

[17] Rojo-Laurillo, M. Defining the Filipino Texter and Texting Style: A Sociolinguistic Analysis of Text Messaging in the Philippines.2005. Retrieved May 13, 2006 from http://www.researchsea.com

[18] Shortis, T. The Language of ICT: Information and Communication Technology. London: Routledge,2001.

[19] Telia/Temo. SMS-undersökning (a survey of SMS use, made by Temo by order of Telia Mobile,Sweden),2002.

[20] Thurlow, C."Generation Txt? Exposing the sociolinguistics of young people's text messaging," Discourse Analysis Online, 1(1),2003.Retrieved March 24, 2006 from http://extra.shu.ac.uk/ daol/articles/open/2002/003/thurlow2002003-paper.html

\section{AUTHORS}

Latisha Asmaak Shafie is a senior lecturer at Universiti Teknologi MARA Perlis, Malaysia.Her fields of interests are emerging learning technologies, workplace English and intercultural communication (e-mail: ciklatisha@perlis.uitm.edu.my).

Norizul Azida Darus is a senior lecturer at Universiti Teknologi MARA Perlis, Malaysia. Her fields of interests are second language acquisition and life-long learning.(email: norizulazida@perlis.uitm.edu.my)

Nazira Osman is a lecturer at Universiti Teknologi MARA Perlis, Malaysia.Her fields of interests are second language acquisition and spoken discourse. (e-mail: naziraosman@perlis.uitm.edu.my).

This work was supported in part by Universiti Teknologi MARA.

Manuscript received 09 July 2009. Published as resubmitted by the authors February 12, 2010. 